\title{
Motivações dos discentes do Programa de Pós-graduação em Direito da Universidade Federal do Paraná (UFPR) para publicar em periódicos científicos no domínio do Direito
}

Paula Carina de Araújo

\begin{abstract}
Doutoranda do Programa de Pós-graduação em Ciência da Informação da Universidade Estadual Júlio de Mesquita Filho (UNESP), Mestre em Ciência, Gestão e Tecnologia da Informação pela UFPR, Bibliotecária com Habilitação em Gestão da Informação pela Universidade do Estado de Santa Catarina (UDESC). Bibliotecária na Biblioteca de Ciências Jurídicas do Sistema de Bibliotecas da Universidade Federal do Paraná (UFPR) Docente do Curso de Biblioteconomia a Distância da Universidade de Caxias do Sul (UCS)
\end{abstract}

Sandra Miguel

Diretora do Departamento de Bibliotecologia e Professora Titular do Instituto de Investigaciones en Humanidades y Ciencias Sociales - IdIHCS (UNLP-CONICET), Facultad de Humanidades $y$ Ciencias de la Educación, Universidad Nacional de La Plata, Argentina.

http://dx.doi.org/10.1590/1981-5344/2710

Busca conhecer as motivações e dificuldades dos discentes do Programa de Pós-Graduação em Direito (PPGD) da Universidade Federal do Paraná (UFPR) para publicar em periódicos científicos. Desenvolve uma pesquisa qualitativa e exploratória e utiliza o questionário como instrumento de coleta de dados. Tem como população da pesquisa os discentes do Programa de PósGraduação em Direito (PPGD) da Universidade Federal do Paraná (UFPR). Classifica as motivações em quatro categorias: científico-profissionais, financeiras/de recompensa, pessoais e tecnológicas. Apresenta o reconhecimento acadêmico advindo da produção intelectual e/ou científica como a motivação mais importante para os respondentes. Destaca a baixa disponibilidade de tempo para pesquisar e escrever como a principal dificuldade considerada pelos alunos. Indica o 
tempo prolongado para avaliação dos artigos submetidos aos periódicos científicos como uma dificuldade além das previstas na pesquisa, especialmente, quando os artigos fazem parte de um estrato privilegiado do Qualis da CAPES. Identifica alto grau de similaridade entre os resultados desta pesquisa e de outras realizadas no Brasil sobre motivações para publicar em periódicos científicos.

Palavras-chave: Motivação; Produção científica; Periódico Científico; Pós-Graduação em Direito; Comunicação científica.

\section{Motivations of the students of the Graduate Program in Law of the Federal University of Paraná (UFPR) to publish in scientific journals in the field of Law}

The aim of the article is to know the motivations of students of Program of Post-graduate in Law from Universidade Federal do Paraná (UFPR) to publish in scientific journals. It develops a qualitative and exploratory research and it uses the questionary as a data collection instrument. The population of the research are the students of Program of Post-graduate in Law from UFPR. The article classifies the motivations in four categories: scientific-professional, financial/reward, personal and technological. It shows the academic recognition from intellectual production as the most important motivation for the students. The paper also highlights the low availability of time to research and write as the main difficulty. It indicates the long time to evaluate the articles submitted to scientific journals as a difficulty besides those cited in the research, especially when the journals are classified in the highest levels of Qualis from Coordenação de Aperfeiçoamento de Pessoal de Nível Superior (CAPES). It also identifies similarities among the results of this research and others that were conducted in Brazil about motivations to publish in scientific journals. 
Keywords: Motivation - Scientific production; Scientific Journal; Postgraduate in Law; Scientific communication.

Recebido em18.02.2016 Aceito em 23.09.2016

\section{Introdução}

Para conhecer determinado domínio, vários fatores devem ser analisados. Conhecer as características relacionadas à produção científica e ao comportamento dos atores envolvidos é essencial para esse reconhecimento, tendo em vista que as publicações são o principal produto proveniente do trabalho dos pesquisadores. Côrtes (2006, p. 53) explica que há um novo paradigma relacionado à comunicação científica na atualidade, impulsionado pela difusão do conhecimento científico e pelos novos modelos de publicações.

É da pós-graduação que emana a maioria das pesquisas desenvolvidas no Brasil. A Coordenação de Aperfeiçoamento de Pessoal de Nível Superior (CAPES) é a responsável pela avaliação do desempenho dos programas de pós-graduação brasileiros. Para isso, "adota cinco quesitos com pesos diferentes na composição da nota final: proposta do programa; corpo docente; corpo discente, teses e dissertações; produção intelectual e inserção social". (CASTANHA; GRÁCIO, 2015, p.131)

Um dos critérios é relacionado à produção intelectual, o que ocasiona uma busca para publicar cada vez mais documentos científicos individuais e em colaboração intra e interinstitucional. A preferência dos autores é por periódicos científicos de excelência, uma vez que é o tipo de publicação com maior peso nas avaliações, o que pode ser constatado nos documentos de área da CAPES para as diversas áreas do conhecimento.

Além disso, desde o surgimento das primeiras publicações periódicas científicas, há um entendimento pela comunidade científica de que é reponsabilidade do pesquisador comunicar o que está sendo pesquisado. $\mathrm{E}$ essas publicações têm como objetivo divulgar o que está sendo pesquisado, obter o reconhecimento dos seus pares e muitas vezes da comunidade em geral. "Talvez seja possível afirmar que o processo de comunicação científica desencadeou o modo de lidar com o conhecimento científico determinado pela sua estrutura baseada na produção científica". (WEITZEL, 2006, p. 90).

Diante desse contexto, é importante tratar das motivações e dificuldades encontradas pelos pesquisadores para publicar em periódicos científicos, considerados um dos principais meios de comunicação científica. Portanto, o objetivo geral deste artigo é conhecer as motivações e dificuldades dos discentes do Programa de Pós-Graduação em Direito da Universidade Federal do Paraná (UFPR) para publicar em periódicos científicos.

Os estudos de Adami (2004), Marchiori e Adami (2006) e Ferreira, Marchiori e Cristofoli (2009; 2010) pesquisaram as motivações e 
dificuldades dos pesquisadores das áreas de Ciência da Comunicação e Ciência da Informação e foram tomados como base para a elaboração desta pesquisa, especialmente para a estruturação do instrumento de coleta de dados. Esta pesquisa utiliza os mesmos critérios e categorias de análise porque facilita estudos comparativos futuros, tornando mais significativo o estudo.

Acredita-se que o estudo da produção científica na área jurídica é importante e precisa ser mais explorado. O interesse por conhecer as motivações dessa população deve-se ao fato da autora ser bibliotecária da Biblioteca de Ciências Jurídicas, unidade de informação que atende o Programa de Pós-Graduação em Direito. Além disso, há a necessidade de aprofundar as pesquisas na área para verificar o panorama atual da publicação jurídica em periódicos, tendo em vista que, até recentemente, a produção científica em livros era a mais expressiva. Por fim, outro fator que justifica a realização da pesquisa é o fato de a autora já ter realizado uma pesquisa sobre a mesma temática com os docentes do Setor de Ciências Jurídicas da UFPR (ARAÚJO, 2013).

\section{Produção científica em periódicos científicos}

As duas formas principais de comunicação científica são a fala e a escrita. Para esta pesquisa, interessa conhecer sobre a comunicação escrita que, segundo Meadows (1999, p. 3) teve sua origem com as obras dos gregos, com destaque para Aristóteles.

As revistas científicas são canais formais de comunicação da ciência e surgiram "como uma evolução da comunicação informal, que consistia no uso de cartas, atas ou memórias das reuniões científicas para transferência da informação entre pesquisadores". (GONÇALVES; RAMOS; CASTRO, 2006, p. 165).

Os primeiros periódicos científicos surgiram na segunda metade do século XVII em Paris, com o protagonismo do Journal des Sçavans, cujo "primeiro número foi publicado em 5 de janeiro de 1665". No mesmo ano, em Londres, foi publicado o periódico Philosophical Transactions. O Journal des Sçavans é considerado o precursor do periódico moderno de humanidades e o Philosophical Transactions o precursor do moderno periódico científico. (MEADOWS, 1999, p. 5, 7).

Ambos surgiram durante um período em que pequenos grupos se reuniam para debater questões filosóficas quando organizaram reuniões periódicas em Londres, logo após a Restauração. Essas reuniões deram origem à Royal Society, organização que sempre se interessou pela comunicação, tendo em vista que seus fundadores eram influenciados pelo pensamento de Francis Bacon, que defendia que entre as funções das instituições de pesquisa estariam a coleta e a análise de informações importantes. A partir desse pensamento, os pesquisadores da época buscavam informações sobre novas ideias e pesquisas em outros países e 
essas informações começaram a se acumular, por isso a solução encontrada foi criar uma publicação impressa. (MEADOWS, 1999, p. 5).

Price (1976, p. 40-41) afirma que o surgimento dos periódicos científicos representou a esperança de pôr fim a uma sobrecarga de informação e, mais do que isso, "a publicação original de artigos curtos por autores individuais foi uma evidente inovação na vida da ciência e, como todas as inovações, encontrou nos cientistas uma resistência considerável". Isso se deve ao fato de, até aquele momento, os pesquisadores estarem acostumados à publicação em livros.

A comunicação situa-se no próprio coração da ciência. É para ela tão vital quanto a própria pesquisa, pois a esta não cabe reivindicar com legitimidade este nome enquanto não houver sido analisada e aceita pelos pares. Isso exige, necessariamente, que seja comunicada. (MEADOWS, 1999, p. vii).

A partir dessa perspectiva é possível afirmar que a função principal das revistas científicas "é o registro e a difusão do conhecimento científico existente, favorecendo a comunicação entre pesquisadores e as comunidades científicas $e$, consequentemente, contribuindo para 0 desenvolvimento, atualização e avanços científicos". (GONÇALVES; RAMOS; CASTRO, 2006, p. 171).

A partir do contexto apresentado até aqui, pode-se afirmar que a produção científica tem como principal meio de comunicação o periódico científico, que é voltado tanto para a comunicação do conhecimento quanto para fomentar a comunicação entre os pares das diversas áreas do conhecimento. Miranda e Pereira (1996, p.380) argumentam que o periódico é o meio primário de disseminar os resultados de uma pesquisa e de contribuir para desenvolver o conhecimento $[. . .]^{\prime \prime}$.

Os periódicos científicos "[...] constituem a fonte documental principal que registra, organiza e expressa a produção científica, produção esta que é medida a partir do número e impacto dos artigos e outras comunicações publicadas em periódicos científicos". (PACKER; MENEGHINI, 2006, p. 237).

Ao argumentar que o estudo da comunicação científica por meio dos periódicos científicos é uma prática comum para explorar tendências da literatura científica e avaliar e produção de artigos, Bufrem (2006, p. 194) defende que é por meio desse tipo de produção que é possível conhecer e entender a história da construção intelectual de diferentes domínios.

Não somente o estudo da produção científica, mas a compreensão das motivações para o seu desenvolvimento é essencial para o conhecimento de um domínio. Ao questionar como a comunicação científica se organizou para auxiliar nas atividades da comunidade científica, Meadows (1999, p. 2) afirma que para responder a esse questionamento é preciso reconhecer o que motiva os pesquisadores, 0 porquê de pesquisar. Ele apresenta uma resposta baseado em Francis Bacon, afirmando que a conquista de novos conhecimentos é explicada por duas razões: "pelo que isso representa em si mesmo e por causa de 
suas aplicações". Explica ainda que, segundo Bacon, o aumento do conhecimento está ligado à sua comunicação e esse conhecimento se conserva nos livros e periódicos, entre outros meios de comunicação, e também "geram e lançam suas sementes nas mentes dos outros, provocando e causando ações e opiniões infinitas em eras subseqüentes". (MEADOWS, 1999, p. 2).

Tendo em vista que a universidade é um dos locais onde a produção de conhecimento é constante e considerada uma premissa, estudos relacionados à produção científica envolvendo as publicações e seus agentes são primordiais. Meadows (1999, p. viii) explica que o ambiente universitário é o mais aberto e mais complexo no que diz respeito à comunicação científica. Além disso, nesse contexto todos os ramos do conhecimento avançam juntos, o que possibilita comparações adequadas.

No Brasil, a maioria dos periódicos científicos é vinculada às universidades ou comunidades científicas e profissionais e em menor número a instituições de pesquisa. Eles "não funcionam como parte de um negócio editorial, como é o caso da maioria dos periódicos de qualidade dos países desenvolvidos. Ao contrário, grande parte carece ainda de modelos de financiamento sustentável". (PACKER, 2014, p. 303).

Reconhecer as motivações para publicar em periódicos científicos pode ser considerado um entendimento básico para "identificar aspectos críticos relacionados às medidas de produtividade científica indicadas em levantamentos bibliométricos, entre outros, justificando as razões da maior ou menor produtividade nas diferentes áreas do conhecimento". Além disso, busca-se estimular "as instituições para que adotem postura motivadora frente ao crescente potencial de realização de pesquisas". (ADAMI; MARCHIORI, 2005, p. 75).

Também é possível afirmar que "os motivos do envolvimento com a pesquisa evidentemente se relacionam com os motivos da comunicação científica". (MEADOWS, 1999, p. 81). "A motivação dos pesquisadores pode, analogamente, ser analisada em termos tanto do indivíduo (fatores psicológicos) quanto da comunidade de pesquisa (fatores sociológicos)". (MEADOWS, 1999, p. 82). É objetivo deste estudo analisar a motivação dos discentes do ponto de vista individual, como será evidenciado na apresentação e análise dos dados.

\section{Trajetória metodológica}

Para identificar as motivações e dificuldades dos alunos do Programa de Pós-Graduação em Direito (PPGD) da Universidade Federal do Paraná (UFPR), foi desenvolvida uma pesquisa quanti-qualitativa e descritivainterpretativa. Dessa forma, pretende-se elucidar os traços e características da produção científica na área jurídica por meio da opinião dos seus atores, nesse caso específico, os discentes do PPGD/UFPR.

Foi obtida uma lista composta pelos nomes e e-mails dos alunos regulares do PPGD na secretaria do programa. A partir dessa lista foi 
identifica a população da pesquisa, formada por 149 alunos. Foi enviado aos alunos um questionário eletrônico composto por 20 questões, sendo 7 de múltipla escolha, 6 abertas e outras 7 para as quais foi utilizada a Escala Likert de cinco pontos (1-5) para o respondente indicar seu grau de concordância/importância.

Foram considerados 14 itens motivacionais para a elaboração do questionário, os quais foram obtidos a partir do que Ferreira, Marchiori e Cristofoli (2010) propuseram ao identificar as motivações dos pesquisadores das áreas de Ciência da Comunicação e Ciência da Informação. Os dados estão apresentados em quatro categorias motivacionais estabelecidas na pesquisa de Marchiori e Adami (2006), com destaque para as motivações consideradas mais importantes em cada categoria (pontuação 5 na Escala Likert) pelos respondentes para a análise dos dados.

A ferramenta utilizada para a elaboração do questionário eletrônico foi o Google Drive. O instrumento de coleta de dados foi enviado por email no dia 30 de julho de 2015 para todos os alunos da PPGD da UFPR. O envio do questionário foi repetido nos dias 13 de agosto de 2015 e 20 de agosto de 2015 para alcançar um número maior de respondentes. Foram respondidos 56 questionários, totalizando $37,5 \%$ dos discentes do PPGD da UFPR.

\section{Apresentação e análise dos resultados}

A partir do questionário aplicado aos alunos do PPGD da UFPR, obteve-se a caracterização dos respondentes, tendo sido possível identificar suas motivações e dificuldades para publicar em periódicos científicos, o que será apresentado neste capítulo.

\subsection{Caracterização dos respondentes}

Responderam ao questionário 56 alunos do Programa de PósGraduação em Direito, o que representa $37,5 \%$ dos alunos do programa. Entre os respondentes, $34(60,7 \%)$ são alunos de doutorado e 22 $(39,3 \%)$ de mestrado. Os alunos foram questionados se são, ou não, bolsistas. A maioria, $44(78,6 \%)$, disse não ter bolsa na pós-graduação. Outros 12 respondentes afirmaram ser bolsistas, sendo que $8(14,3 \%)$ tem bolsa da CAPES, $2(3,6 \%)$ do CNPq e outros 2 possuem outros tipos de bolsas.

O PPGD da UFPR é estruturado em três áreas de concentração, as quais abrangem seis linhas de pesquisa. Com o intuito de caracterizar os respondentes, eles foram questionados sobre a área de concentração e a linha de pesquisa das suas dissertações e teses. Do total de alunos, 23 indicaram a área de concentração "Direito das Relações Sociais, outros 23 apontaram "Direito do Estado" e 10 responderam "Direitos Humanos e Democracia". A linha de pesquisa com maior representatividade foi 
"Perspectivas da Dogmática Crítica", uma vez que 16 alunos que responderam ao questionário desenvolvem pesquisas nessa linha.

Quando questionados sobre a participação ou não em grupos de pesquisa, $85,7 \%$ responderam que fazem parte de algum grupo de pesquisa e 14,3\% afirmaram não participar. A participação em grupos de pesquisa acaba levando os pós-graduandos a publicarem suas pesquisas por meio dos diversos canais de comunicação científica, pois esses grupos têm como objetivo fazer ciência e chegar a novas descobertas, pesquisar e divulgar o que estudam.

Entre os respondentes, a maioria, 31 deles (55,3\%), informou ter até cinco publicações em periódicos científicos, o que representa uma significativa frequência para pesquisadores em formação, como é o caso dos pesquisados neste estudo. Em seguida, $11(19,6 \%)$ alunos indicaram ter de 6 a 10 publicações em periódicos científicos. É curioso notar que 6 $(10,7 \%)$ respondentes ainda não publicaram nenhum artigo em periódicos científicos.

Eles também foram questionados se já publicaram alguma vez em periódicos de acesso aberto e 36 respondentes (64,3\%) disseram que sim. Outra pergunta questionava em qual tipo de periódico eles costumam publicar e a maioria, 20 (38,5\%), indicou periódicos tradicionais e de acesso aberto. Entre os pesquisadores, 16 (30,8\%) afirmaram publicar apenas em periódicos de acesso aberto e 13 (25\%) disseram que o fazem somente em revistas tradicionais.

Esses dados deixam evidente o crescimento da divulgação da produção científica em periódicos de acesso aberto. Para Weitzel (2006, p. 103), é a ênfase no acesso que trouxe alguns aspectos importantes que caracterizam o acesso aberto, tais como o "acesso livre à literatura científica; trabalho cooperativo em rede; amplo diálogo entre várias esferas antes alijadas do processo [...]; a relação política entre acesso à informação e direitos humanos; recrudescimento de ações para o controle bibliográfico $[\ldots]^{\prime \prime}$.

Quando questionados sobre o grau de importância de cada um dos formatos de comunicação da produção científica para o domínio do Direito, o livro foi considerado o mais importante por 41 respondentes (73,2\%). Em segundo lugar ficou o artigo científico $(34 / 60,7 \%)$ e, em terceiro, o capítulo de livro $(23 / 41,1 \%)$. Os anais científicos foram considerados os menos importantes.

Como o livro foi indicado o canal preferencial de publicação dos respondentes desta pesquisa, é possível questionar se eles não encontrariam dificuldades ainda maiores caso a publicação em livros tivesse um peso maior no processo de avaliação, tendo em vista a extensão do trabalho e o tempo despendido, além de todo o processo editorial.

Entretanto, ao analisar a planilha comparativa da avaliação trienal da CAPES da área do Direito, foi possível perceber que, especialmente no Curso de Pós-graduação em Direito da UFPR, a produção científica em 
capítulos de livros e coletâneas consideradas pela CAPES é bem mais expressiva que as publicações em periódicos científicos classificados nos principais estratos do Qualis. (BRASIL, 2014).

Esses resultados não surpreendem, especialmente se considerada a atuação da autora em uma biblioteca jurídica, já que suas observações pessoais mostram que a busca por livros tem sido maior que por artigos científicos e anais de congresso. Desse ponto de vista, também é possível identificar o grau de importância dos tipos de publicação para o domínio.

\subsection{Motivações para publicar em periódicos científicos}

A maioria das atividades que as pessoas realizam no seu dia a dia pressupõe algum tipo de motivação para realizá-las e com a produção científica não é diferente. Isso é confirmado por Godoi (2001, p. 86) ao afirmar que "os motivos precedem a tarefa, não são intrínsecos a ela". Para este estudo, toma-se emprestada a definição da autora para motivação. Ao estudar as categorias de motivação na aprendizagem, ela concluiu que motivação é "o conjunto de processos implicados na ativação, direção, intensidade e persistência da conduta". (GODOI, 2001, p. 16).

Ao estudar as motivações dos pesquisadores da área de Comunicação e Ciência da Informação, Marchiori e Ferreira (2008, p. 5) constataram que "[...] devido às diversas alterações que ocorrem no fluxo da produção científica e no formato e proposta das revistas acadêmicocientíficas, urge que se tenha uma visão mais abrangente dos motivos que levam usuários a pesquisar e publicar em portais abertos", o que era objetivo da pesquisa das autoras.

Levando em consideração as particularidades das Ciências Jurídicas e seus canais de publicação preferenciais, apresentados anteriormente neste capítulo, são apresentadas no Quadro 1 as motivações dos discentes do PPGD da UFPR. Essas motivações foram classificadas em quatro categorias, a saber: científico-profissionais, financeiras/de recompensa, pessoais e tecnológicas. Em relação às pesquisas de Ferreira, Marchiori e Cristofoli (2010) e de Marchiori e Adami (2006), foram adicionadas a este estudo a motivação científico-profissional - "cumprir com as exigências do Programa de Pós-Graduação do qual faço parte" - e a motivação financeira/de recompensa - "cumprir com as exigências dos órgãos de fomento à pesquisa (CAPES, CNPq, Fundação Araucária etc.) para alunos bolsistas". 
Tabela 1 - Motivação dos alunos do Programa de Pós-Graduação em Direito da UFPR para publicar em revistas científicas

\begin{tabular}{|c|c|c|c|c|c|}
\hline CATEGORIAS DE MOTIVACÕES & \multicolumn{5}{|c|}{ ESCALA LIKERT } \\
\hline CIENTÍFICO-PROFISSIONAIS & 1 & 2 & 3 & 4 & 5 \\
\hline $\begin{array}{l}\text { Oportunidade de disseminar informações e } \\
\text { conhecimentos }\end{array}$ & $\begin{array}{c}2 \\
3,6 \% \\
\end{array}$ & $\begin{array}{c}3 \\
5,4 \% \\
\end{array}$ & $\begin{array}{c}7 \\
12,5 \%\end{array}$ & $\begin{array}{c}15 \\
26,8 \%\end{array}$ & $\begin{array}{c}29 \\
51,8 \%\end{array}$ \\
\hline $\begin{array}{l}\text { Possibilidade de contribuir com fontes de informação } \\
\text { para novas pesquisas }\end{array}$ & $\begin{array}{c}2 \\
3,6 \%\end{array}$ & $\begin{array}{c}6 \\
10,7 \%\end{array}$ & $\begin{array}{c}4 \\
7,1 \%\end{array}$ & $\begin{array}{c}16 \\
28,6 \%\end{array}$ & $\begin{array}{c}28 \\
50 \%\end{array}$ \\
\hline $\begin{array}{l}\text { Oportunidade de submeter a produção intelectual à } \\
\text { revisão e avaliação dos pares }\end{array}$ & $\begin{array}{c}4 \\
7,1 \%\end{array}$ & $\begin{array}{c}6 \\
10,7 \%\end{array}$ & $\begin{array}{c}8 \\
14,3 \%\end{array}$ & $\begin{array}{c}15 \\
26,8 \%\end{array}$ & $\begin{array}{c}23 \\
41,1 \%\end{array}$ \\
\hline $\begin{array}{l}\text { Oportunidade de escrever e publicar artigos em } \\
\text { colaboração com outros pesquisadores }\end{array}$ & $\begin{array}{c}7 \\
12,5 \%\end{array}$ & $\begin{array}{c}6 \\
10,7 \%\end{array}$ & $\begin{array}{c}13 \\
23,2 \%\end{array}$ & $\begin{array}{c}21 \\
37,5 \%\end{array}$ & $\begin{array}{c}9 \\
16,1 \%\end{array}$ \\
\hline $\begin{array}{l}\text { Cumprir com as exigências do Programa de Pós- } \\
\text { Graduação do qual faço parte }\end{array}$ & $\begin{array}{c}6 \\
10,7 \%\end{array}$ & $\begin{array}{c}4 \\
7,1 \%\end{array}$ & $\begin{array}{c}13 \\
23,2 \%\end{array}$ & $\begin{array}{c}14 \\
25 \%\end{array}$ & $\begin{array}{c}19 \\
33,9 \%\end{array}$ \\
\hline FINANCEIRAS/DE RECOMPENSAS & 1 & 2 & 3 & 4 & 5 \\
\hline $\begin{array}{l}\text { Influência do sistema de recompensa associado à } \\
\text { carreira universitária }\end{array}$ & $\begin{array}{c}16 \\
28,6 \%\end{array}$ & $\begin{array}{c}5 \\
8,9 \%\end{array}$ & $\begin{array}{c}9 \\
16,1 \%\end{array}$ & $\begin{array}{c}10 \\
17,9 \%\end{array}$ & $\begin{array}{c}16 \\
28,6 \%\end{array}$ \\
\hline $\begin{array}{l}\text { Facilidade advinda do fato de integrar Conselho } \\
\text { Editorial de revistas científicas }\end{array}$ & $\begin{array}{c}34 \\
60,7 \%\end{array}$ & $\begin{array}{c}13 \\
23,2 \%\end{array}$ & $\begin{array}{c}7 \\
12,5 \%\end{array}$ & $\begin{array}{c}2 \\
3,6 \%\end{array}$ & 0 \\
\hline $\begin{array}{l}\text { Participação em programas de pós-graduação stricto } \\
\text { sensu }\end{array}$ & $\begin{array}{c}9 \\
16,1 \%\end{array}$ & $\begin{array}{c}8 \\
14,3 \%\end{array}$ & $\begin{array}{c}6 \\
10,7 \%\end{array}$ & $\begin{array}{c}11 \\
19,6 \%\end{array}$ & $\begin{array}{c}22 \\
39,3 \%\end{array}$ \\
\hline $\begin{array}{l}\text { Cumprir com as exigências dos órgãos de fomento à } \\
\text { pesquisa (CAPES, CNPq, Fundação Araucária, etc) } \\
\text { para alunos bolsistas }\end{array}$ & $\begin{array}{c}25 \\
44,6 \%\end{array}$ & $\begin{array}{c}5 \\
8,9 \%\end{array}$ & $\begin{array}{c}8 \\
14,3 \%\end{array}$ & $\begin{array}{c}8 \\
14,3 \%\end{array}$ & $\begin{array}{c}10 \\
17,9 \%\end{array}$ \\
\hline PESSOAIS & 1 & 2 & 3 & 4 & 5 \\
\hline Prestígio profissional proporcionado aos autores & $\begin{array}{c}9 \\
16,1 \%\end{array}$ & $\begin{array}{c}4 \\
7,1 \%\end{array}$ & $\begin{array}{c}11 \\
19,6 \%\end{array}$ & $\begin{array}{c}18 \\
32,1 \%\end{array}$ & $\begin{array}{c}14 \\
25 \%\end{array}$ \\
\hline $\begin{array}{l}\text { Reconhecimento acadêmico advindo da produção } \\
\text { intelectual e/ou científica }\end{array}$ & $\begin{array}{c}2 \\
3,6 \%\end{array}$ & $\begin{array}{c}3 \\
5,4 \%\end{array}$ & $\begin{array}{c}4 \\
7,1 \%\end{array}$ & $\begin{array}{c}16 \\
28,6 \%\end{array}$ & $\begin{array}{c}31 \\
55,4 \%\end{array}$ \\
\hline Possibilidade de ser citado pelos pares & $\begin{array}{c}9 \\
16,1 \%\end{array}$ & $\begin{array}{c}6 \\
10,7 \%\end{array}$ & $\begin{array}{c}12 \\
21,4 \%\end{array}$ & $\begin{array}{c}16 \\
28,6 \%\end{array}$ & $\begin{array}{c}13 \\
23,2 \%\end{array}$ \\
\hline $\begin{array}{l}\text { Oportunidade de assegurar a prioridade de descobertas } \\
\text { e estabelecer a propriedade intelectual }\end{array}$ & $\begin{array}{c}22 \\
39,3 \%\end{array}$ & $\begin{array}{c}8 \\
14,3 \%\end{array}$ & $\begin{array}{c}16 \\
28,6 \%\end{array}$ & $\begin{array}{c}8 \\
14,3 \%\end{array}$ & $\begin{array}{c}2 \\
3,6 \%\end{array}$ \\
\hline TECNOLÓGICAS & 1 & 2 & 3 & 4 & 5 \\
\hline $\begin{array}{l}\text { Facilidade associada ao ambiente da internet, o qual } \\
\text { imprime agilidade ao processo de submissão, de } \\
\text { publicação e de disseminação de artigos }\end{array}$ & $\begin{array}{c}5 \\
8,9 \%\end{array}$ & $\begin{array}{c}7 \\
12,5 \%\end{array}$ & $\begin{array}{c}14 \\
25 \%\end{array}$ & $\begin{array}{c}11 \\
19,6 \%\end{array}$ & $\begin{array}{c}19 \\
33,9 \%\end{array}$ \\
\hline $\begin{array}{l}\text { Revistas impressas: respeitado o tempo para a } \\
\text { avaliação por pares }\end{array}$ & $\begin{array}{c}9 \\
16,1 \%\end{array}$ & $\begin{array}{c}7 \\
12,5 \%\end{array}$ & $\begin{array}{c}17 \\
30,4 \%\end{array}$ & $\begin{array}{c}14 \\
25 \%\end{array}$ & $\begin{array}{c}9 \\
16,1 \%\end{array}$ \\
\hline $\begin{array}{l}\text { Revistas eletrônicas: rapidez na publicação, respeitado } \\
\text { o tempo para avaliação por pares }\end{array}$ & $\begin{array}{c}3 \\
5,4 \%\end{array}$ & $\begin{array}{c}6 \\
10,7 \%\end{array}$ & $\begin{array}{c}17 \\
30,4 \%\end{array}$ & $\begin{array}{c}12 \\
21,4 \%\end{array}$ & $\begin{array}{c}18 \\
32,1 \%\end{array}$ \\
\hline
\end{tabular}

Fonte: Dados da pesquisa.

Ao observar a Tabela 1, é possível inferir que a "oportunidade de disseminar informações e conhecimentos" é a motivação científicoprofissional mais importante para os alunos do PPGD da UFPR, com 29 indicações $(51,8 \%)$. Quanto à segunda motivação mais importante, destaca-se "a possibilidade de contribuir com fontes de informação para novas pesquisas", que recebeu o índice 5 da Escala Likert por 28 alunos $(50 \%)$.

A partir desses dados, percebe-se que, mesmo com as inúmeras cobranças com relação à produção científica na pós-graduação, ainda predomina o desejo de compartilhar o conhecimento e fomentar novas 
pesquisas como motivação científico-profissional. Nesse contexto, a motivação "cumprir com as exigências do Programa de Pós-Graduação do qual faço parte" recebeu 19 indicações $(33,9 \%)$ como a mais importante.

Entretanto, em outra categoria de motivações, a financeira/de recompensa, a "participação em programas de pós-graduação stricto sensu" foi considerada a mais importante por 22 discentes (39,3\%). Em segundo lugar, foi apontada a "influência do sistema de recompensa associado à carreira universitária", com 16 (28,6\%) indicações. Esses resultados estão totalmente vinculados ao modelo da pós-graduação brasileiro.

Os resultados relacionados à categoria "motivações financeiras/de recompensa" são explicados pelo fato de dois itens de avaliação dos programas de pós-graduação serem o corpo discente, teses e dissertações e a produção intelectual. A CAPES avalia especialmente a produção científica dos docentes, mas sabe-se que é essencial a publicação em colaboração com os discentes e outros docentes.

O "reconhecimento acadêmico advindo da produção intelectual e/ou científica" foi considerado a motivação mais importante por $31(55,4 \%)$ discentes. Sabe-se que esse reconhecimento pode ser revertido em convites para participar de eventos científicos e em grupos de pesquisa, recebimento de pontuação em processos seletivos para docentes, tendo em vista que a docência é um dos objetivos da maioria das pessoas que cursam a pós-graduação stricto sensu, dentre outros.

Além disso, sabe-se que essa é uma das funções dos periódicos científicos, validar as pesquisas que são publicadas, tendo em vista que passam pela avaliação por pares e por critérios de avaliação de qualidade elevados, principalmente os periódicos classificados nos principais estratos $(A 1, A 2, B 1)$ do Qualis da CAPES e/ou em publicações internacionais de alto nível.

Ainda foi indicado, como segunda motivação mais importante, com 14 indicações (25\%), o "prestígio profissional proporcionado aos autores", muito atrelado à motivação indicada em primeiro lugar. Note-se que a "possibilidade de ser citado pelos pares" ficou em terceiro lugar segundo o grau de importância, com 13 (23,2\%) indicações.

Compreende-se que as três primeiras motivações estão diretamente relacionadas, pois uma das formas de reconhecimento acadêmico e de obtenção de prestígio profissional se dá por meio das citações aos trabalhos do pesquisador. Há muitos anos, os estudiosos da área de análise de citações já procuram explicar as razões para citar (CARVALHO, 1975; BAVELAS, 1978; ALVARENGA, 1998; VANZ; CAREGNATO, 2003). O ato de citar envolve questões psicológicas, sociológicas, políticas e históricas. (ALVARENGA, 1998).

A "facilidade associada ao ambiente da internet, o qual imprime agilidade ao processo de submissão, de publicação e de disseminação de artigos" foi considerada a principal motivação tecnológica com 19 (33,9\%) indicações. A segunda motivação mais indicada foi "revistas eletrônicas: 
rapidez na publicação, respeitado o tempo para avaliação por pares", por $18(32,1 \%)$ respondentes.

Os respondentes ainda foram questionados se havia outras motivações não citadas no questionário e algumas foram indicadas. Um dos alunos afirmou que a publicação de um artigo significa a materialização da pesquisa e gera satisfação pessoal e sentimento de missão cumprida, para ele um fator motivador para novas pesquisas. Outro aluno alegou que publica por acreditar no seu objeto de pesquisa e na ciência como campo de consolidação da realidade.

O modelo de avaliação da CAPES também foi citado como fator motivador. Um dos alunos escreveu que uma melhoria no índice de produtividade extraído dos dados incluídos no Lattes poderia ser considerada uma motivação. Outro discente citou como motivação uma maior pontuação e incentivo pela CAPES.

\subsection{Dificuldades para publicar em periódicos científicos}

Foram apresentadas aos respondentes dificuldades de ordem pessoal e de ordem diversa. Coube a eles indicar, utilizando a Escala Likert, o grau de importância onde 1 representa o menor e 5, o maior. Também foi proposta uma questão aberta para que os alunos pudessem indicar outras dificuldades não previstas no estudo. Os dados obtidos são apresentados na Tabela 2 e, posteriormente, é realizada a análise dos mesmos.

Tabela 2 - Dificuldades dos alunos do Programa de Pós-Graduação em Direito da UFPR para publicar em revistas científicas

\begin{tabular}{|c|c|c|c|c|c|}
\hline DIFICULDADES & \multicolumn{5}{|c|}{ ESCALA LIKERT } \\
\hline DE ORDEM PESSOAL & 1 & 2 & 3 & 4 & 5 \\
\hline Baixa disponibilidade de tempo para pesquisar e escrever & $\begin{array}{c}4 \\
7,1 \% \\
\end{array}$ & $\begin{array}{c}5 \\
8,9 \% \\
\end{array}$ & $\begin{array}{c}12 \\
21,4 \% \\
\end{array}$ & $\begin{array}{c}15 \\
26,8 \% \\
\end{array}$ & $\begin{array}{c}20 \\
35,7 \% \\
\end{array}$ \\
\hline Dificuldade em obter fontes de informação atualizadas & $\begin{array}{c}17 \\
30,4 \% \\
\end{array}$ & $\begin{array}{c}13 \\
23,2 \%\end{array}$ & $\begin{array}{c}13 \\
23,2 \% \\
\end{array}$ & $\begin{array}{c}6 \\
10,7 \%\end{array}$ & $\begin{array}{c}7 \\
12,5 \%\end{array}$ \\
\hline Maior parte da literatura da área em outros idiomas & $\begin{array}{c}32 \\
57,1 \% \\
\end{array}$ & $\begin{array}{c}10 \\
17,9 \% \\
\end{array}$ & $\begin{array}{c}8 \\
14,3 \% \\
\end{array}$ & $\begin{array}{c}2 \\
3,6 \% \\
\end{array}$ & $\begin{array}{c}4 \\
7,1 \% \\
\end{array}$ \\
\hline Participação restrita em grupos de pesquisa & $\begin{array}{c}27 \\
48,2 \% \\
\end{array}$ & $\begin{array}{c}12 \\
21,4 \% \\
\end{array}$ & $\begin{array}{c}9 \\
16,1 \% \\
\end{array}$ & $\begin{array}{c}6 \\
10,7 \% \\
\end{array}$ & $\begin{array}{c}2 \\
3,6 \% \\
\end{array}$ \\
\hline $\begin{array}{l}\text { Preferência por outros formatos e canais de comunicação, } \\
\text { como relatórios e eventos }\end{array}$ & $\begin{array}{c}38 \\
67,9 \% \\
\end{array}$ & $\begin{array}{c}11 \\
19,6 \% \\
\end{array}$ & $\begin{array}{c}1 \\
1,8 \% \\
\end{array}$ & $\begin{array}{c}4 \\
7,1 \% \\
\end{array}$ & $\begin{array}{c}2 \\
3,6 \% \\
\end{array}$ \\
\hline DE ORDEM DIVERSA & & & & & \\
\hline $\begin{array}{l}\text { Alto grau de dispersão de artigos sobre um mesmo tema } \\
\text { entre as revistas da área }\end{array}$ & $\begin{array}{c}16 \\
28,6 \% \\
\end{array}$ & $\begin{array}{c}11 \\
19,6 \% \\
\end{array}$ & $\begin{array}{c}14 \\
25 \% \\
\end{array}$ & $\begin{array}{c}9 \\
16,1 \% \\
\end{array}$ & $\begin{array}{c}6 \\
10,7 \% \\
\end{array}$ \\
\hline $\begin{array}{l}\text { Excesso de informações: tema de interesse repetitivamente } \\
\text { publicado em revistas }\end{array}$ & $\begin{array}{c}13 \\
23,2 \%\end{array}$ & $\begin{array}{c}12 \\
21,4 \%\end{array}$ & $\begin{array}{c}15 \\
26,8 \%\end{array}$ & $\begin{array}{c}9 \\
16,1 \%\end{array}$ & $\begin{array}{c}7 \\
12,5 \%\end{array}$ \\
\hline $\begin{array}{l}\text { Dificuldade em encontrar pares dispostos a escrever em } \\
\text { colaboração }\end{array}$ & $\begin{array}{c}19 \\
33,9 \% \\
\end{array}$ & $\begin{array}{c}11 \\
19,6 \% \\
\end{array}$ & $\begin{array}{c}11 \\
19,6 \%\end{array}$ & $\begin{array}{c}6 \\
10,7 \% \\
\end{array}$ & $\begin{array}{c}9 \\
16,1 \%\end{array}$ \\
\hline
\end{tabular}

Fonte: Dados da pesquisa.

A dificuldade de ordem pessoal mais indicada foi a "baixa disponibilidade de tempo para pesquisar e escrever", com 20 indicações $(35,7 \%)$ para o índice 5 da Escala Likert. Curioso é perceber que as 
dificuldades consideradas menos importantes nessa categoria foram "preferência por outros formatos e canais de comunicação, como relatórios e eventos", com 38 indicações $(67,9 \%)$, e "maior parte da literatura da área em outros idiomas", com $32(57,1 \%)$ indicações.

As indicações para as dificuldades de ordem diversa ficaram muito pulverizadas. É possível perceber que um número grande de respondentes indicou a "dificuldade em encontrar pares dispostos a escrever em colaboração" como uma dificuldade menos importante. A segunda dificuldade menos importante mais indicada foi o "alto grau de dispersão de artigos sobre um mesmo tema entre as revistas da área".

Portanto, percebe-se que a colaboração para a realização da pesquisa é uma realidade no domínio do direito, pois essa não foi considerada uma dificuldade pelos alunos do PPGD da UFPR. Nesse contexto, cabe destacar o pensamento de Pisciotta (2006, p. 117), quando explica que "a comunicação científica ocorre quando as relações entre as pessoas e entre as instituições se estabelecem, à medida que se estabelecem as articulações entre os pares e dos pares com a sociedade".

Além das dificuldades apresentadas para os alunos indicarem o grau de importância, eles tiveram a oportunidade de citar outras que consideram relevantes. Dois discentes indicaram que a elevada carga horária de disciplinas obrigatórias do PPGD da UFPR aliada ao grande volume de leituras relacionadas a essas disciplinas dificultam o processo de produção científica, tendo em vista que essas disciplinas obrigatórias nem sempre têm relação com o tema da tese ou dissertação.

Também foi indicada como dificuldade para dois alunos a necessidade de publicar em parceria com um doutor ou doutorando para que o seu artigo seja aceito em uma revista que segue as recomendações da CAPES e dos principais indexadores. Além disso, o fato de estar no início da carreira acadêmica também é citado como dificuldade. Nessa mesma linha, também foi apontada a questão da exogenia, que é um dos critérios de avaliação dos periódicos. Foi destacado que as revistas dos programas de pós-graduação não refletem a produção científica da própria instituição, mas uma miscelânea de pesquisas de outras instituições.

Sabe-se que todos esses critérios exigidos pelos periódicos científicos existem devido à busca por qualificação junto aos órgãos financiadores e avaliadores da qualidade do periódico, bem como 0 cumprimento dos critérios para indexação nos principais agregadores (Scopus, Web of Science, Scielo etc), o que também é considerado um índice de qualidade. Os periódicos científicos não têm o mesmo prestígio e influência na comunidade científica e esse reconhecimento está diretamente vinculado à sua qualidade e visibilidade. E essas questões preocupam a todos os que participam do processo de produção científica em toda a América Latina. (MIGUEL, 2011). Ainda que seja considerado contraditório e injusto por muitos pesquisadores, esta é a condição que está posta e cabe aos atores envolvidos se posicionarem a favor ou buscarem novas alternativas. 
Ainda foi citada como dificuldade a demora para avaliação dos artigos submetidos aos periódicos. Três alunos apresentaram essa problemática, o que é explicado pelo fato de a maioria dos periódicos científicos não ter uma equipe estruturada para a editoração científica e manutenção de todo o processo editorial. Por esse motivo, são crescentes as ações que buscam a profissionalização das equipes editoriais.

Packer (2014, p. 317-318) apresenta duas inovações no processo de comunicação científica que podem sanar a dificuldade apontada pelos alunos. A primeira é a publicação individual de artigos à medida em que eles são recebidos e passam pelo processo de peer review. Com a crescente publicação de periódicos científicos eletrônicos, não há mais obrigatoriedade de atrelar a publicação aos fascículos, os quais podem ser formados na medida em que os artigos vão sendo publicados individualmente. A segunda inovação é a "racionalização da tarefa de revisão por pares, por meio do compartilhamento de pareceres entre periódicos". Os periódicos enfrentam grande dificuldade para conseguir pareceristas ad hoc para avaliação. O autor acredita que "a união de periódicos em plataformas compartilhadas de gestão de manuscritos e publicação, emulando megajournals, poderá ser uma solução para os periódicos do Brasil".

Foram relatadas dificuldades com relação ao formato dos artigos, como a quantidade de páginas, de 20 a 25 páginas para a área do Direito, bem como a diversidade e clareza das normas para formatação dos artigos de uma revista para outra. Também foi argumentado que a pesquisa não é ensinada e estimulada durante a graduação na área do direito e isso dificulta o envolvimento com essa atividade quando o aluno é admitido na pós-graduação, além de haver pouca ou nenhuma divulgação pelas instituições universitárias acerca das revistas nas quais é possível publicar. As bibliotecas universitárias podem auxiliar para minimizar essas dificuldades, oferecendo curso de capacitação em pesquisa e compartilhando dicas sobre publicações em periódicos científicos. Cabe destacar que muitas bibliotecas universitárias já oferecem esses serviços.

Um dos respondentes critica a pressão para publicar preferencialmente ou exclusivamente em periódicos, condição que, na visão dele, leva ao cumprimento de um requisito formal da produção científica, mas olvida o debate e restringe a eficácia dialógica que a academia deveria propiciar.

\section{Considerações finais}

Entre todas as motivações, a considerada mais importante pelos respondentes foi de ordem pessoal: "o reconhecimento acadêmico advindo da produção intelectual e/ou científica". Esse resultado difere do que foi constatado na pesquisa de Araújo (2013) em estudo similar realizado com os docentes do Setor de Ciências Jurídicas da UFPR, os 
quais indicaram "a oportunidade de disseminar informações e conhecimentos" como a mais importante, mesmo resultado obtido por Ferreira, Marchiori e Cristofoli (2010).

$O$ fato do reconhecimento acadêmico ser considerado a principal motivação para publicar em periódicos para os discentes do PPGD da UFPR pode ser explicado pela circunstância de que esses atores estão em formação na pós-graduação e por ser um período em que é extremamente importante se tornar conhecido por meio de publicações científicas. Sabese que essa é uma das formas de avaliação do aluno e também avaliação futura para concorrer a uma posição como docente, por exemplo. O que difere do docente, como constatado na pesquisa de Araújo (2013), uma vez que este já obteve reconhecimento acadêmico, precisa apenas mantêlo.

A principal dificuldade para publicar em periódicos científicos foi a baixa disponibilidade de tempo para pesquisar e escrever, mesma dificuldade encontrada na pesquisa realizada com os docentes (ARAúJO, 2013) e com os pesquisadores das áreas de ciência da comunicação e ciência da informação (FERREIRA; MARCHIORI; CRISTOFOLI, 2010). Essa pode ser considerada uma característica comum para os alunos de pósgraduação, tendo em vista o grande volume de trabalho (publicações, disciplinas etc.) exigido pelos programas e pela CAPES. Provavelmente, é uma característica comum aos estudantes de outros domínios também.

Apesar de muitos programas de pós-graduação exigirem dedicação integral aos estudos, sabe-se que isso não é possível, uma vez que o número de bolsas não atende a todos os alunos do programa, o que ficou evidente neste estudo, já que a maioria dos respondentes não recebe bolsa. Por isso, muitos conciliam os estudos com o trabalho e a vida familiar.

Além disso, o oferecimento de elevada carga horária de disciplinas obrigatórias pelo PPGD/UFPR também está diretamente relacionado à baixa disponibilidade de tempo para pesquisar e escrever. Para minimizar essa dificuldade, sugere-se que o programa não seja baseado em disciplinas obrigatórias, como já acontece em muitas pós-graduações, mas que os alunos e seus orientadores possam escolher as disciplinas que pretendem cursar e, dessa forma, cumpram o número de créditos exigidos. Assim, teriam a oportunidade de escolher as disciplinas que têm relação com o tema da tese ou dissertação e poderiam aprofundar suas pesquisas na área do seu interesse e otimizar o tempo.

Cabe ainda destacar que as dificuldades apontadas não são necessariamente relacionadas apenas a dificuldades para publicar especificamente em periódicos científicos, mas a todo o processo de pesquisa e publicação em que o aluno de pós-graduação está envolvido.

Percebe-se que muitas dificuldades apresentadas neste estudo decorrem do modelo de avaliação atual da pós-graduação brasileira e, por consequência, do modelo dos periódicos científicos que, na sua maioria, 
são vinculados às universidades. Há inúmeras discussões e estudos para verificar se o modelo vigente é o melhor.

A busca para publicar nos melhores periódicos, ou seja, aqueles com qualis elevado, é inerente ao modelo de avaliação atual. Entretanto, as questões aqui apresentadas não seriam resolvidas se, por exemplo, os pesquisadores resolvessem deixar de publicar nesses periódicos de prestígio e passassem a publicar em periódicos sem qualis. Afinal, a questão da qualidade não pode ser esquecida. Entretanto, é preciso que sejam repensados os modelos de avaliação da pós-graduação para que não seja tão custoso todo esse processo.

Foi possível constatar que o novo paradigma da comunicação científica apresentado por Côrtes (2006), abordado na introdução desta pesquisa, é confirmado ao identificar, em uma área tão tradicional como o direito, que a publicação na forma de artigos científicos é a segunda mais comum entre os pesquisadores em questão.

Seguindo esse mesmo pensamento, a publicação em periódicos tradicionais e de acesso aberto demonstra a busca por acompanhar as mudanças relacionadas à produção e comunicação científica. Apesar de ainda haver muitas editoras que monopolizam o mercado editorial da área jurídica no Brasil e que não privilegiam o acesso aberto. Com isso, não se quer afirmar que as motivações e dificuldades apresentadas nesta pesquisa tenham relação com o modelo de publicação e o acesso a essa produção. Mas esses são fatores que não podem ser deixados de lado, tendo em vista que evidenciam como o domínio vem se comportando.

Nesta pesquisa, pode-se apontar como uma das limitações o baixo número de respondentes, se comparado à população envolvida. Ainda assim, foi possível obter resultados reveladores e similares ao de estudos realizados anteriormente, o que possibilitou uma rica comparação e importantes constatações.

As motivações e dificuldades apresentadas nesta pesquisa confirmam o que foi constatado em outras pesquisas já citadas anteriormente. Sugere-se como pesquisa futura a realização de um estudo sobre motivações e dificuldades para publicar em periódicos científicos junto a outras áreas do conhecimento, como Ciências Exatas e Ciências da Saúde, que diferem das Ciências Sociais Aplicadas e podem apresentar resultados passíveis de comparação

\section{Referências}

ADAMI, A. Produção e consumo de conteúdo em revistas científicas: um estudo sobre a motivação de autores e leitores. 2004. 90f. Trabalho de conclusão de curso. (Graduação em Gestão da Informação) - Setor de Ciências Sociais Aplicadas, Universidade Federal do Paraná, Curitiba, 2004. 
ADAMI, A.; MARCHIORI, P. Z. Autoria e leitura de artigos por docentes pesquisadores: motivações e barreiras. In: FERREIRA, S. M. S. P.; TARGINO, M. das G. (Org.). Preparação de revistas científicas: teoria e prática. São Paulo: Reichmann \& Autores, 2005. p. 73-100.

ALVARENGA, L. Bibliometria e Arqueologia do Saber de Michel Foucault: traços

de identidade teórico-metodológica. Ciência da Informação, Brasília, DF, v. 27, n. 3,set./dez. 1998. Disponível em: <http://www.scielo.br/scielo.php?script=sci_arttext\&pid=S010019651998000300002 >. Acesso em: 20 out. 2002.

ARAÚJO, P. C. de. Motivação dos docentes do Setor de Ciências Jurídicas da Universidade Federal do Paraná para publicar em periódicos científicos. In: ENCONTRO NACIONAL DE PESQUISA EM CIÊNCIA DA INFORMAÇÃO, 14., 2013. Anais... Florianópolis: UFSC, 2013. Disponível em: <http://enancib.sites.ufsc.br/index.php/enancib2013/XIVenancib/paper/vi ew/491/445>. Acesso em: 20 nov. 2015

BAVELAS, J. B. The social psychology of citations. Canadian Psychological Review, Calgary, v. 19, n. 2, p. 158-163, 1978. Disponível em: <http://search.proquest.com/openview/fbc5ef13e437feae6912b97ee030c f60/1 ?pq-origsite=gscholar $>$. Acesso em: 18 nov. 2015.

BRASIL. Coordenação de Aperfeiçoamento de Pessoal de Nível Superior. Planilhas comparativas da avaliação trienal: Direito. Brasília, DF: CAPES, 2014. Disponível em: <http://www.avaliacaotrienal2013.capes.gov.br/resultados/planilhascomparativas>. Acesso em: 27 nov. 2015.

BUFREM, L. S. Revistas científicas: saberes no campo de Ciência da Informação. In: POBLACION, D. A.; WITTER, G. P.; SILVA, J. F. M. da (Orgs.). Comunicação \& produção científica: contexto, indicadores e avaliação. São Paulo: Angellara, 2006. p.191-214.

CARVALHO, M. M. de. Análises bibliométricas da literatura de química

no Brasil. Ciência da Informação, Brasília, DF, v. 4, n. 2, p. 119-141, 1975. Disponível em: <http://revista.ibict.br/ciinf/article/view/56>. Acesso em: $10 \mathrm{dez} .2015$.

CASTANHA, R. C. G.; GRÁCIO, M. C. C. Contribuição da análise multivariada para os indicadores de avaliação dos programas de pósgraduação: uma análise na área de Matemática (2007-2009). Em questão, v. 21, n. 2, jan./abr. 2015. Disponível em: <http://goo.gl/rx0z7S>. Acesso em: 20 nov. 2015.

CÔRTES, P. L. Considerações sobre a evolução da ciência e da comunicação científica. In: POBLACION, D. A.; WITTER, G. P.; SILVA, J. F. M. da (Orgs.). Comunicação \& produção científica: contexto, indicadores e avaliação. São Paulo: Angellara, 2006. p. 33-55. 
FERREIRA, S. M. S. P.; MARCHIORI, P.; CRISTOFOLI, F. Motivação para publicar em revistas científicas: estudo nas áreas de ciências da comunicação e ciência da informação. In: FERREIRA, S. M. S. P.; TARGINO, M. das G. (Org.). Acessibilidade e visibilidade de revistas científicas eletrônicas. São Paulo: Ed. Senac São Paulo; Cengage Learning, 2010. p. 79-118.

FERREIRA, S. M. S. P.; MARCHIORI, P.; CRISTOFOLI, F. Fatores motivacionais da comunidade científica para publicação e divulgação de sua produção em revistas/repositórios científico-acadêmicos: um estudo com grupos de autores-pesquisadores e Ciências da Comunicação e Ciência da Informação/Biblioteconomia. São Paulo; Curitiba: ECA-USP; DECiGI-UFPR, 2009.

GODOI, C. K. Categorias da motivação na aprendizagem. 2001.

417f. Tese (Doutorado em Engenharia de Produção) - Programa de PósGraduação em Engenharia de Produção, UFSC, Florianópolis.

GONÇALVES, A.; RAMOS, L. M. S. V. C.; CASTRO, R. C. F. Revistas científicas: características, funções e critérios de qualidade. In: POBLACION, D. A.; WITTER, G. P.; SILVA, J. F. M. da (Orgs.). Comunicação \& produção científica: contexto, indicadores e avaliação. São Paulo: Angellara, 2006. p. 163-190.

MARCHIORI, P. Z.; ADAMI, A. Motivação e produção científico-acadêmica: o impacto das novas tecnologias da informação e da comunicação sob o ponto de vista dos autores. In: INTERCOM SUL. SIMPÓSIO DE PESQUISA EM COMUNICAÇÃO, 7., 2006. Livro de programas e resumos. Curitiba: UFPR, 2006. v. 1. p. 1-18.

MARCHIORI, P. Z.; FERREIRA, S. M. S. P. Estudos de percepção e motivação de pesquisadores frente às revistas e repositórios científicos digitais de acesso aberto: uma proposta metodológica. In: Coloquio Administración y Liderazgo en el Campo Informativo, 2008. Satisfacción de usuarios: evaluación integral de bibliotecas: ponencias. Veracruz, México: Universidad Veracruzana, 2008. p. 1-26.

MEADOWS, A. J. A comunicação científica. Brasília: Briquet de Lemos, 1999.

MIGUEL, S. Revistas y producción científica de América Latina y el Caribe: su visibilidad en SciELO, RedALyC y SCOPUS. Revista Interamericana de Bibliotecología, Medellín, Colombia, v. 34, n. 2, p. 187-199, 2011. Disponível em: <http://aprendeenlinea.udea.edu.co/revistas/index.php/RIB/article/view/ 10306/9522>. Acesso em: 20 ago. 2015.

MIRANDA, D. B. de; PEREIRA, M. de N. F. O periódico científico como veículo de comunicação: uma revisão de literatura. Ciência da Informação, Brasília, v. 25, n. 3, p. 375-382, set./dez. 1996. Disponível em: 
<http://revista.ibict.br/ciinf/index.php/ciinf/article/viewFile/462/421>. Acesso em: 1 set. 2014.

PACKER, A. L. A eclosão dos periódicos do Brasil e cenários para o seu porvir. Educação e Pesquisa, São Paulo, v. 40, n. 2, p. 301-323, abr./jun. 2014. Disponível em: <http://submission.scielo.br/index.php/ep/article/view/132544/8731>. Acesso em: 22 nov. 2015.

PACKER, A. L.; MENEGUINI, R. Visibilidade da produção científica. In: POBLACION, D. A.; WITTER, G. P.; SILVA, J. F. M. da (Orgs.). Comunicação \& produção científica: contexto, indicadores e avaliação. São Paulo: Angellara, 2006. p. 237-259.

PISCIOTTA, K. Redes sociais: articulação com os pares e com a sociedade. In: POBLACION, D. A.; WITTER, G. P.; SILVA, J. F. M. da (Orgs.). Comunicação \& produção científica: contexto, indicadores e avaliação. São Paulo: Angellara, 2006. p. 115-136.

PRICE, D. J. de S. O desenvolvimento da ciência: análise histórica, filosófica, sociológica e econômica. Rio de Janeiro: Livros Técnicos e Científicos Editora, 1976.

VANZ, S. A. de S.; CAREGNATO, S. E. Estudo de citação: uma ferramenta para entender a comunicação científica. Em Questão, Porto Alegre, v. 9, n. 2, p. 295-307, jul./dez. 2003. Disponível em: <http://goo.gl/yKH78t>. Acesso em: 22 nov. 2015.

WEITZEL, S. da R. Fluxo da informação científica. In: POBLACION, D. A.; WITTER, G. P.; SILVA, J. F. M. da (Orgs.). Comunicação \& produção científica: contexto, indicadores e avaliação. São Paulo: Angellara, 2006. p. $81-114$. 